EYE CONTACT

() 


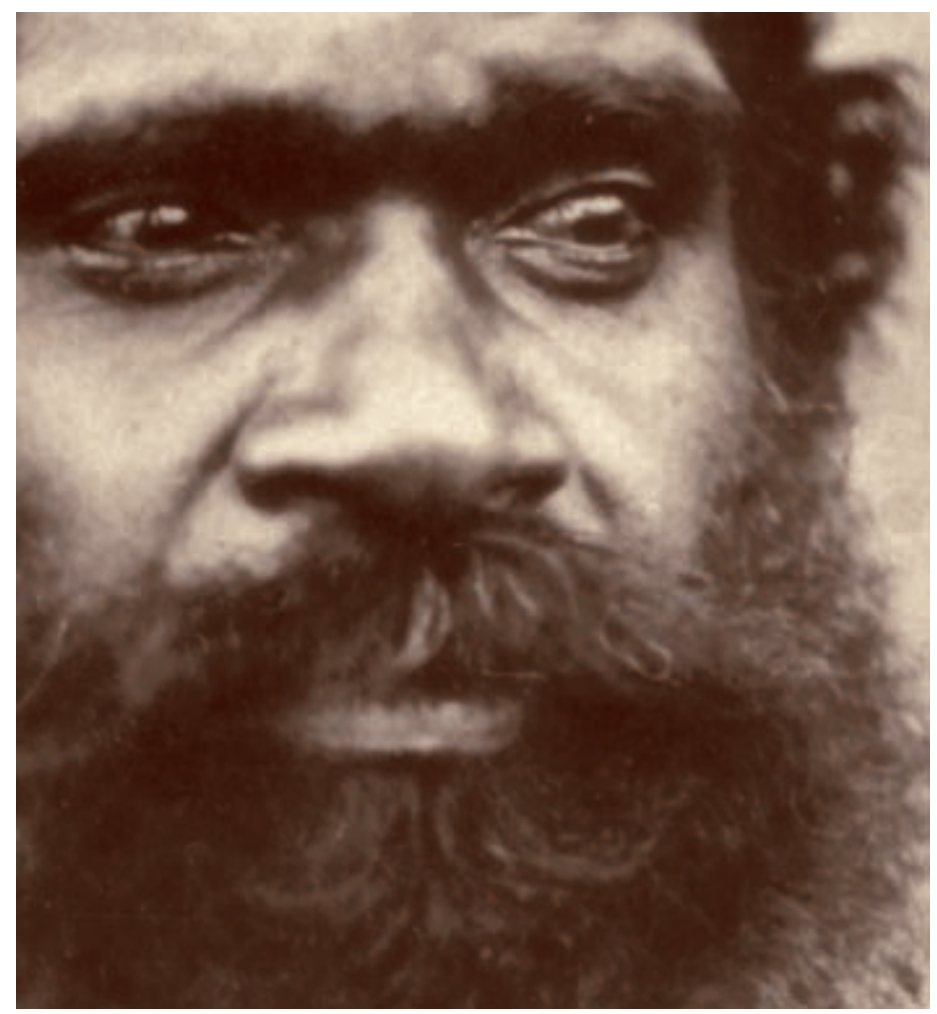

OBJECTS/HISTORIES

CRITICAL PERSPECTIVES ON ART, MATERIAL CULTURE,

AND REPRESENTATION

A SERIES EDITED BY NICHOLAS THOMAS

Published with the assistance of the Getty Foundation 


\section{EYE CONTACT}

PHOTOGRAPHING INDIGENOUS AUSTRALIANS

\section{JANE LYDON}

(๑)

DUKE UNIVERSITY PRESS

Durham and London

2005 
๑) 2005 DUKE UNIVERSITY PRESS

ALL RIGHTS RESERVED

PRINTED IN HONG KONG

ON ACID-FREE PAPER @

DESIGNED BY AMY RUTH BUCHANAN

TYPESET IN DANTE BY TSENG

INFORMATION SYSTEMS, INC

LIBRARY OF CONGRESS CATALOGING-

IN-PUBLICATION DATA APPEAR ON THE

LAST PRINTED PAGE OF THIS BOOK. 


\section{For my mother}


